\title{
A abordagem hermenêutica nos estudos da tradução ${ }^{1}$
}

\author{
Bernd Stefanink ${ }^{2}$ \\ Ioana Bălăcescu ${ }^{3}$ \\ Tradução de Diana Fortier ${ }^{4}$ \\ A relevância de uma teoria da tradução \\ é medida pela forma como ela lida com a criatividade. ${ }^{5}$
}

\section{Por que precisamos da abordagem hermenêutica nos estudos da tradução?}

Tese: Porque é o mais próximo que se pode chegar de uma prática tradutória ideal, que se concentra na tradução de significados, não de palavras.

Características: $\mathrm{O}$ que fundamentalmente caracteriza a hermenêutica é o fato de unir subjetividade, corporalidade e criatividade em sua reflexão teórica.

\subsection{Subjetividade}

A Hermenêutica da Tradução integra a subjetividade do tradutor em sua abordagem teórica por considerar que isso é inevitável. Os resultados recentes das pesquisas cognitivas demonstraram inegavelmente esse fato. Por exemplo, o neurofilósofo Hans Lenk ${ }^{6}$ pontou que, quando percebemos um objeto, nosso cérebro o separa em partes antes de sintetizá-lo novamente, a fim de permitir sua compreensão. Algumas áreas do cérebro registram o tamanho do objeto, outras a cor, e assim por diante. Quando vemos uma Golden Delicious, que é uma maçã muito comum na Europa, registramos sua forma, sua cor, até mesmo seu cheiro e peso, tudo em diferentes áreas do cérebro, que então associa essas características à categoria maçã e nela armazena a informação. Esse é um processo

\footnotetext{
${ }^{1}$ Original em inglês, em Cadernos de.Tradução, v. 37, n. 3 (2017), 21-52.

${ }^{2}$ Professor na Universidade de Bielefeld. Desde 2007 pesquisa e ensina na Herder Foundation/DAAD. De agosto de 2015 a Julho de 2016, atuou como professor visitante na Universidade Federal de Santa Catarina/Brasil. E-mail: bstefanink@hotmail.com.

${ }^{3}$ PhD em "Tradução: Didática e Criatividade" (Universidade de Craiova; 2005). 2006-2007: Bolsa de pesquisa de pós-doutorado da fundação Humboldt na TU Darmstadt e Bielefeld University (Supervisores: Radegundis Stolze e Bernd Stefanink). Atua na Universidade de Craiova /Romênia, Departamento de Linguística Aplicada. Contato: ioanadi@hotmail.com.

${ }^{4}$ Professora de Língua Inglesa no Curso de Letras-Inglês da Universidade Federal do Ceará. Contato: fortier.diana@gmail.com.

${ }^{5}$ STEFANINK, Bernd; BĂL ĂCESCU, Ioana. Les cheminements de la créativité en traduction. META 60.3. 2015, p. 600.

${ }^{6}$ LENK, Hans. Methodologischer chemainterpretationismus: Erkenntnistheoretisches zur Einführung. In: PAUL, Gregor. Transkulturelle Logik. Universalität in der Vielfalt. Bochum Freiburg: Projektverlag, 2014.
} 
de categorização: "Compreender significa categorizar"7 .

Mas quais são essas categorias em nossa mente? Elas são o resultado de nosso vécu, que é o resultado das experiências recorrentes em nossa vida cotidiana. É como um caminho pelo meio da floresta. Depois de abrir uma trilha na selva, você usará o mesmo caminho da próxima vez, mesmo que este faça um pequeno desvio, já esta trilha já está aberta e você não terá que lutar mais uma vez contra o matagal para seguir caminho. Experimentos empíricos mostraram que é assim que o cérebro reage e influencia o comportamento humano.

No nosso cérebro, essa trilha é o caminho neural através do qual os neurônios trazem informações ao cérebro. Quanto mais você usa o mesmo caminho neural, mais forte ele se torna e se transforma em um engrama, ou seja, um traço de memória [Gedächtnisspur]. Como o conexionismo ${ }^{8}$ nos ensina: é a frequência das repetições que fortalece o caminho. Os diferentes caminhos formam uma rede neural, baseada em nossas experiências pessoais, através da qual percebemos as novas informações recebidas.

Portanto, essa rede neural influencia nossa percepção por meio de associações com nosso déjà vécu. Isso pode ser observado em um experimento muito simples, descrito por Fillmore ${ }^{9}$. Uma professora relata esse experimento: ela entrou na sala de aula com uma toranja e começou descascar a fruta, retirando fatias finas da casca. Ao terminar, perguntou aos alunos qual era o fruto que ela havia descascado. A resposta foi: uma laranja. Isso significa que os alunos interpretaram sua ação através do conhecimento que eles tinham sobre o manuseio de frutas. Para eles, obviamente, uma toranja era algo que você corta ao meio com uma faca e come com uma colher. Fillmore ${ }^{10}$ conclui: "A função categorizadora das palavras ainda não havia sido libertada da cena das pessoas em sua experiência de comer a fruta”.

Até mesmo esse simples exemplo mostra que interpretamos quando tentamos entender, e que essa interpretação é subjetiva, ligada, neste caso, a hábitos culturais, o habitus de Bourdieu ${ }^{11}$. Esse exemplo também apoia a ideia hermenêutica sobre a maneira como adquirimos significado: através da categorização ${ }^{12}$.

Temos aqui um aspecto do círculo hermenêutico: para compreender algo, precisamos já ter uma ideia do novo objeto que estamos vendo ou das novas informações que estamos obtendo, para assim poder categorizá-lo, sendo a categorização a base do processo de compreensão. Do contrário, caso não tenhamos a menor ideia do que estamos vendo, não conseguiremos compreender. Essa rede neuronal que influencia nossa percepção é, certamente, subjetiva.

Para o tradutor, isso significa dizer que, ao tentar entender um texto, ele inevitavelmente já projeta uma certa pré-compreensão que tem do mesmo. Heidegger chama isso de pré-compreensão (Vorverständnis), os cognitivistas

\footnotetext{
${ }^{7}$ LAKOFF, George; JoHnSOn, Mark. Metaphors We Live By. Chicago: University of Chicago Press, 1980, p.5.

${ }^{8}$ SCHADE, Ulrich. Konnektionismus: Zur Modellierung der Sprachproduktion. Opladen: Westdeutscher Verlag, 1992.

${ }^{9}$ Fillmore, Charles. Scenes-and-Frames Semantics. In: ZAMPOLLI, Antonio (dir.) Linguistic Structures Processing, Amsterdam: N. Holland, 1976, p. 62.

${ }^{10}$ Ibidem

${ }^{11}$ BOURDIEU, Pierre. Le Sens pratique. Paris: Les Éditions de Minuit, 1980.

${ }^{12}$ BĂLĂCESCU, Ioana; STEFANINK, Bernd. Kognitivismus und übersetzerische Kreativität. In: Lebende Sprachen n.2. 2006.
} 
usam o termo script. O tradutor irremediavelmente aproxima-se do texto com tal pré-compreensão em mente. Esse script, é claro, está suscetível a inevitáveis mudanças no decorrer da leitura. Quanto mais o tradutor avança na leitura do texto, mais esse significado preconcebido se torna completo, ou seja, em harmonia com o real significado do texto para ele. O tradutor alemão Radegundis Stolze ${ }^{13}$ introduz o termo Stimmigkeit para descrever essa harmonia. Para o tradutor hermenêutico, a tradução está completa ou stimmig quando o texto alvo coincide com a representação mental do significado do texto fonte, presente no cérebro do tradutor.

Essa concepção hermenêutica é corroborada por pesquisas cognitivistas, como ilustrado pela descrição do processo de compreensão de Fillmore ${ }^{14}$, por exemplo:

A primeira parte do texto ativa uma imagem ou cena de certa situação na mente do intérprete; partes posteriores do texto acrescentam cada vez mais informações sobre tal situação, fornecem uma história, uma motivação, inserem-na em outros cenários ou situações, e assim por diante. Ou seja, ao se compreender um texto, cria-se mentalmente uma espécie de mundo; as características desse mundo podem depender bastante das experiências pessoais do próprio intérprete, uma realidade que deve explicar em parte o fato de que diferentes pessoas constroem interpretações diferentes do mesmo texto.

O exemplo anterior de Fillmore, em que ele chega a conclusões a partir do experimento laranja/toranja, implica que, em sua percepção, as palavras que armazenamos em nosso cérebro durante o processo de aquisição do conhecimento são extraídas do contexto cênico e armazenadas independentemente. Esse conceito conduzirá à teoria dos $\mathrm{MOPs}^{15}$, tão importante para nossos esforços em compreender a criatividade no processo tradutório, como apresentado abaixo.

\subsection{Criatividade}

Outro aspecto do cotidiano do tradutor que é frequentemente posto de lado pelos teóricos da tradução é a criatividade. A hermenêutica mostra que a criatividade não é algo misterioso, e sim uma atividade de solução de problemas para superar barreiras culturais. Uma teoria que exclui essa criatividade de suas considerações por esta não ser sistematizável, como fazem alguns teóricos ${ }^{16}$, induz o tradutor inseguro a abandonar brilhantes soluções metafóricas e criativas em favor de opções mais facilmente aceitas de acordo com a lógica, mas mais precárias

\footnotetext{
${ }^{13}$ StOlZE, Radegundis; STANLEY, John; CERCEL, Larisa (eds). Translational Hermeneutics. The First Symposium. București: Zeta Books, 2015.

${ }^{14}$ FILLMORE, op. cit., p.61.

${ }^{15}$ SCHANK, Roger, C. Dynamic Memory. A Theory of Reminding and Learning in Computers and People, London/New York: Cambridge University Press, 1982.

${ }^{16}$ GerZymisCh-ARBOGast, Heidrun; MudersbaCH, Klaus. Methoden des wissenschaflichen Übersetzens. Tübingen: Francke, 1998, p. 16.
} 
comunicativamente e menos expressivas, empregando assim estratégias "seguras" para evitar críticas, já que não saberiam como responder a tais questionamentos. A hermenêutica ajuda a dissipar essas críticas. Ela acredita que essas traduções "seguras" muitas vezes traem os textos originais pois carecem do "tom" do texto ${ }^{17}$.

Além disso, com base nos resultados de pesquisas recentes em ciência cognitiva, a hermenêutica incentiva a criatividade do tradutor na resolução de problemas tradutórios, fazendo uso do que os cognitivistas chamam de pensamento lateral $^{18}$ ou pensamento divergente ${ }^{19}$, que pode ser adquirido mediante treinamento e ajuda o tradutor a encontrar soluções para superar os problemas criados pelas barreiras culturais.

\subsection{O Valor Epistemológico das Metáforas}

E com esse intuito de incentivar a criatividade, a hermenêutica também faz uso das descobertas da ciência cognitiva sobre o valor epistemológico das metáforas. Às vezes, o significado encontrado nas "entrelinhas", como afirma Schleiermacher, pode ser melhor comunicado através de metáforas, e a hermenêutica legitima seu uso.

Hans-Georg Gadamer abordou a questão de como o conceito de metáfora pode ser resgatado do cânone aristotélico e redefinido como uma porta de entrada para uma interpretação que lance novas luzes sobre o próprio ato de conhecer. Em sua discussão do tema, dois tipos de significado nos permitem opor uma concepção retórica de metáfora a uma outra percepção que expresse uma relação espontânea com o que sabemos. Dessa forma, a metáfora não é somente um conceito teórico, mas introduz a ideia de "ver como" no processo de cognição propriamente dito. Esse valor epistemológico da metáfora é cientificamente comprovado através de pesquisas cognitivas, como mostrado acima ${ }^{20}$.

Vejamos o que Lakoff e Johnson ${ }^{21}$ têm a dizer. A teoria de metáfora de Lakoff e Johnson pode oferecer ao tradutor uma valiosa fonte de legitimação para sua solução criativa de problemas. Os autores presumem o seguinte:

1. A categorização é a base de cada um dos processos de compreensão: "Para compreender o mundo e nele atuar, temos que categorizar" (ibid., p. 162).

2. Essa categorização acontece com base nas "experiências recorrentes" ("as experiências recorrentes levam à formação de categorias" (ibid., p. 230), o que leva à formação de metáforas: "grande parte de nosso sistema conceitual é estruturado através de metáforas" (ibd., p. 147), "nosso sistema conceitual é inerentemente metafórico" (ibd., p. 184).

\footnotetext{
${ }^{17}$ Kohlmayer, Rainer. Die Stimme im Text als tertium comparationis beim Literaturübersetzen. In: STOLZE, Radegundis; STANLEY, John; CerCEL, Larisa (eds). Translational Hermeneutics. The First Symposium. București: Zeta Books, 2015.

${ }^{18}$ DE BONO, E. Lateral Thinking. A Textbook of Creativity. London: Ward Lock Educational, 1970.

${ }^{19}$ GuILFORD, Joy Peter. Creativity: A Quarter Century of Progress. In: TAYLOR, Irving A.; GETZELS, Jacob W. (eds). Perspectives in Creativity. Chicago: Aldine, 1975.

${ }^{20}$ BĂLĂCESCU; STEFANINK, op. cit., 2006.

${ }^{21}$ LAKOFF; JOHNSON, op. cit., 1980.
} 
3. É essencial para as categorizações que estas enfatizem certos aspectos da experiência em detrimento de outros: "Uma categorização é uma forma natural de identificar um indivíduo ou objeto da experiência através da ênfase em certas propriedades em detrimento de algumas e com a omissão de outras” (ibid., p. 163).

4. Isso nos permite obter uma nova compreensão de nossas experiências: "Tais metáforas são capazes de nos dar uma nova compreensão de nossa experiência, [...] destacando algumas coisas e escondendo outras” (ibid., p. 139).

5. Essas metáforas estão interligadas: "as metáforas nos permitem compreender uma área de nossa experiência através de outra. Isso sugere que a compreensão se dá em termos de áreas inteiras da experiência e não através de conceitos isolados" (ibid., p. 117). "As metáforas [c] onceituais estão fundamentadas em correlações dentro de nossa experiência" (ibid., p. 154-155).

6. A rede de metáforas que estrutura nosso conhecimento de mundo difere de cultura para cultura, em função da diferença dos ecossistemas: "Mas os aspectos humanos da realidade são diferentes. [...] Os sistemas conceituais de diferentes culturas dependem do ambiente físico em que elas se desenvolveram" (ibid., p. 146). "Nossas experiências (1) serão diferentes de cultura para cultura" (ibid., p. 154), e (2) poderão depender de nossas experiências em relação a outras, ou seja, nossas experiências podem ser metafóricas por natureza.

Não teríamos aqui, então, a base para a compreensibilidade das estratégias de resolução de problemas associativas-criativas na tradução? A teoria da metáfora e do conexionismo confirmam uma a outra, na medida em que nossas experiências recorrentes, que levam à formação das categorias necessárias para o processo de compreensão, são refletidas em vias neuronais (ou engramas) ativadas de forma coneccionista (e assim intensificadas), que são utilizadas prioritariamente para novas experiências (em termos técnicos: disparadas, ${ }^{22}$ ), conduzindo a um reforço ainda maior.

No nível linguístico, essas experiências recorrentes se refletem como metáforas fraseológicas. Contudo, nossas experiências não estão armazenadas isoladamente, mas - como visto do ponto de vista conexionista - em uma teia dinâmica de caminhos, que são as "implicações metafóricas" que formam toda a rede conceitual com a qual nós compreendemos o mundo. Essas conexões associativas que se confirmam mutualmente no nível neural e também no nível conceitual dão legitimidade ao pensamento associativo enquanto estratégia para solução de problemas. E, se aceitarmos a concepção de Paul Valéry de que uma obra de arte fica suscetível ao entendimento do receptor a partir do momento em que sai das mãos do artista, então toda tradução criativa - assim como toda nova metáfora - é um "destaque", no sentido proposto por Lakoff e Johnson ${ }^{23}$, de aspectos do original que, até então, estiveram ocultos e que podem levar a uma novo compreensão dessa obra original (ponto 4) a partir da perspectiva da

\footnotetext{
${ }^{22}$ SCHADE, Ulrich. Konnektionismus: Zur Modellierung der Sprachproduktion. Opladen: Westdeutscher Verlag, 1992. p.11.

${ }^{23}$ LAKOFF; JOHNSON, op. cit., 1980.
} 
cultura-alvo (no sentido proposto por Bachelard, Derrida, Mavrodin, entre outros representantes da Poiética). A base material das experiências metaforicamente interligadas pode ser encontrada nas vias neurais ou engramas do nosso cérebro, já mencionados.

Não podemos esquecer que, muito antes dos cognitivistas chamarem atenção para o poder epistemológico da metáfora, Percy Bysshe Shelley já havia antecipado tal poder. Pare ele, toda linguagem é poesia, ao invés de simplesmente um meio de comunicação. Shelley alega que a linguagem era originalmente poesia em virtude de seu poder profético de estabelecer uma relação vital com o mundo, uma ideia que também fundamenta o conceito hermenêutico de linguagem de Heidegger. Ao nos basear na leitura de Kant feita por Heidegger e o papel que este atribui à imaginação, podemos ver, na figura que carrega uma tocha na obra Prometeu Desacorrentado, de Shelley, uma metáfora de como um poeta transita entre as esferas da profecia e da cognição, enquanto traduz experiências que, de outra forma, permaneceriam opacas e limitadas.

Quando afirma que o mito literário é uma forma avançada de metáfora, Shelley está prevendo outra ideia hermenêutica que encontramos no conceito de Paul Ricoeur sobre o papel que os mitos desempenhariam em nossa compreensão do mundo. A 'reviravolta hermenêutica' na filosofia de Ricoeur, durante os anos sessenta do século $\mathrm{XX}$, ocorreu devido à sua vontade, enquanto filósofo protestante, de explicar o mal no mundo. Esta foi a origem do desenvolvimento da teoria de interpretação de Ricoeur, que é fundamental para a hermenêutica filosófica, e que contribui fundamentalmente para lançar as bases da abordagem hermenêutica tradutória. Para Ricoeur ${ }^{24}$, a metáfora é "o problema central da hermenêutica" e que existe uma "vérité métaphorique" [verdade metafórica] ${ }^{25}$.

\subsection{A corporalidade da compreensão}

Outro fundamento da hermenêutica que está integrado em sua abordagem teórica é a corporalidade da nossa compreensão. Nossa pesquisa empírica, baseada na análise conversacional etnometodológica, revela um incrível efeito emocional exercido pelos elementos do texto-fonte que apelam para os sentidos do leitor/tradutor. Entender o significado de um texto usando os sentidos é algo que comumente esperamos e admitimos na poesia. Porém, isso não está limitado à poesia, também se dá no caso de outros gêneros textuais. Esse é um dos principais mecanismos utilizados pelos autores com o objetivo de tornar seus textos mais convincentes, apelando para nossos sentimentos, nossas emoções e nossa sensualidade. Por vezes, isso pode dar origem a traduções que nem sempre são aceitas pelo pensamento intelectual lógico. No entanto, a hermenêutica integra essa corporalidade da compreensão em sua abordagem teórica, e empenha-se em dar base científica para ela. Além disso, nossa pesquisa empírica revela que, muito frequentemente, os tradutores não se dão conta do que desencadeou suas soluções criativas para problemas. A abordagem hermenêutica auxilia esses tradutores a analisar o quanto sua compreensão criativa de um texto e suas soluções criativas para sua tradução resultam de suas reações somáticas, como esperamos ter explicado de forma

\footnotetext{
${ }^{24}$ Ricceur, Paul. Ecrits et Conférences. II. Herméneutique. Paris: Seuil. 2010.

${ }^{25}$ RICGeur, Paul. La Métaphore vive. Paris: Seuil, 1975, pp. 11, 310.
} 
convincente em Stefanink e Bălăcescu ${ }^{26}$. Vejamos agora em que contexto científico que a abordagem hermenêutica propriamente dita se desenvolveu.

2. O contexto científico dos estudos da tradução nos anos 70, época em que a Hermenêutica da Iraduçäofoi introduzida. traduzir palauras vs. traduzir significados

Ao ler um texto, não lemos as palavras; em vez disso, o que fazemos é tentar apreender o significado de um texto. Além disso, há também uma diferença entre qualquer leitor de um texto e o tradutor. O leitor padrão compreende o significado intuitivamente. $\mathrm{O}$ tradutor tem que ir além e tornar explícito essa compreensão intuitiva para poder traduzi-la (Auslegung, de Heidegger [explicitação]). A Hermenêutica da Tradução busca encontrar uma metodologia para chegar a esse significado e torná-lo explícito.

Mas: onde está o significado?

\subsection{A evolução gradual de uma visão atomista para uma visão holística do significado,} acompanhando a evolução da unidade de tradução.

Quando a teoria da tradução começou a se desenvolver sistematicamente na segunda metade do século XX, o significado foi considerado, obviamente, como dependente da unidade de tradução.

Ao considerarmos a evolução das teorias de tradução na segunda metade do século XX, vemos claramente que o significado não está nas palavras. Pelo contrário: observamos um desenvolvimento que começa com uma visão atomista (que tentava encontrar o significado dissecando as palavras em suas unidades mínimas de significado) e avança cada vez mais em direção a uma abordagem holística. Essa abordagem holística é um dos fundamentos da hermenêutica tradutória.

\subsubsection{A abordagem estruturalista: a palaura como unidade de tradução}

A abordagem estruturalista, que visava desenvolver um modelo para a tradução automática, tentou apreender o significado das palavras decompondo-as em seus elementos semânticos. Kade, o teórico da tradução mais influente da década de 1960, chegou ao ponto de defender que o processo de entendimento não era necessário e deveria ser evitado, pois implicava na subjetividade do $\operatorname{tradutor}^{27}$. O ato de traduzir consistia em encontrar uma ou mais

\footnotetext{
${ }^{26}$ STEFANINK, Bernd; BĂLĂCESCU, Ioana. Le verbum interius du traducteur et la cristallisation du sens. META 62. 2. August/2017, 290-314.

${ }^{27}$ KADE, Otto. Zufall und Gesetzmäßigkeit in der Übersetzung, Leipzig: VEB Verlag Enzyklopädie, 1968. p. 58.
} 
palavras no idioma de destino que representariam as mesmas características semânticas. Assim, Eugene Nida, o famoso tradutor da Bíblia, escreveu: "O que pretendemos é uma reprodução fiel dos grupos de características componenciais" 2829 . E Georges Mounin, o linguista francês, comparou a tradução à química, que dividia as entidades orgânicas em seus elementos para reconstruí-las sinteticamente, reunindo esses elementos em uma nova entidade. Em Problèmes théoriques de la traduction, ele escreveu: "Si de telles 'particules de sens' [minimales] existaient, la traduction deviendrait quelque chose d'aussi simple que l'analyse et la synthèse en chimie" ${ }^{\text {"20 }}$.

Mas o ALPAC (Comitê Consultivo para Processamento Automático de Idiomas), que avaliava os resultados destas pesquisas, cancelou este programa (em 1966), porque não era eficiente. Havia também muitos mal-entendidos sobre os resultados da tradução automática. O significado do texto não podia ser apreendido dessa maneira.

\subsubsection{A abordagem pragmática: a oração como unidade de tradução. Primeiro passo na compreensão de que o tradutor não encontra o significado nas palauras}

Após o fracasso da abordagem estruturalista, os teóricos da tradução passaram a considerar que o problema estava nas unidades de tradução. A palavra não era suficiente; a pesquisa se estendeu à oração como unidade de tradução, como apontou o linguista inglês John Catford: uma unidade independente que transmite o significado.

$\mathrm{Na}$ tradução como um todo, os textos ou itens da língua fonte e da língua alvo são equivalentes tradutórios quando são intercambiáveis em uma determinada situação. É por isso que a equivalência na tradução pode quase sempre ser estabelecida no nível da oração - a oração é a unidade gramatical mais diretamente relacionada às funções de fala em um contexto de situação ${ }^{31}$.

O resultado disto foi, por exemplo, a stylistique comparée de Vinay e Darbelnet, que procurava encontrar estruturas oracionais que pudessem ter correspondência automática na língua alvo. Outra decorrência foi a teoria dos atos de fala, que, para o tradutor, significava que ele não tinha de se ater às palavras do texto, mas que precisava traduzir o significado pretendido, dependendo da situação em especial, o que foi um primeiro passo para considerar que o significado estava não nas palavras, mas em algo além delas.

\footnotetext{
${ }^{28}$ NIDA, Eugene A. Semantic Structure and Translating. In: WILSS, W.; THOME, G. Aspekte der theoretischen sprachbezogenen und angewandten Uebersetzungswissenschaft II, Heidelberg: Groos, 1974. p. 50.

${ }^{29}$ Onze anos depois, Nida se distanciará dessa visão da tradução centrada sobre a palavra: "Não estamos mais limitados à ideia de que o significado está centrado nas palavras ou mesmo nas distinções gramaticais. Tudo na linguagem, do som ao simbolismo às estruturas retóricas complexas, tem significado" (NIDA, 1985, p. 119).

${ }^{30}$ Mounin, Georges. Les problèmes théoriques de la traduction. Paris: Gallimard, 1963.

${ }^{31}$ CATFORD, J. C. A Linguistic Theory of Translation. An Essay in Applied Linguistics. London, 1965, p. 49.
} 


\subsubsection{O texto como unidade de tradução. A "übersetzerrelevante Textanalyse" (Análise-do-Texto- relevante-para-o-Tradutor) ${ }^{32}$. A teoria das isotopias. A abordagem funcional: "Skopostheorie" 33}

À medida em que a Linguística desenvolveu-se na direção da linguística textual, inaugurada pelo linguista alemão Harald Weinrich, a teoria da tradução sofreu diversos novos impactos. Um resultado muito óbvio desse processo foi a skopostheory, que situava o tradutor como um ator em um ambiente social (de acordo com a teoria da ação). De acordo com a fórmula de Lasswell, o tradutor precisava levar em consideração os “5 Qs": quem está traduzindo o quê para quem, através de que canal e com qual efeito.

Tínhamos aqui um afastamento ainda maior da ideia da palavra como uma unidade de tradução capaz de revelar o significado que o tradutor deveria traduzir.

Outro passo, ainda mais significativo, foi a teoria das isotopias de Algirdas Julien Greimas, desenvolvida em um livro publicado em 1966 com o título Sémantique structurale [Semântica Estrutural]. A ideia de Greimas era de que uma palavra não estava isolada no texto, mas tinha "amigos" que estão ligados entre si, ou, como explica Ludwig Wittgenstein, filósofo alemão: em um texto há palavras que pertencem à mesma família, elas têm Familienähnlichkeiten [semelhanças familiares].

Para Greimas, isto significava que as palavras tinham uma ou mais características semânticas em comum, que para ele eram os componentes semânticos como unidades mínimas de significado, os “semas". Atualmente, é possível estender essa ideia de unidades mínimas comuns para uma semelhança mais geral e falar, por exemplo, de uma isotopia de ironia em um texto, que é baseada em um conjunto de palavras que transmitem tal significado.

A teoria das Isotopias de Greimas foi um passo importante no caminho para a hermenêutica tradutória. Com a teoria da isotopia, o significado de uma palavra deve ser considerado em relação às outras palavras que fazem parte da mesma isotopia. E o significado do texto emerge da rede de isotopias que estruturam o texto. Seguindo a afirmação de Schleiermacher de que o significado está "nas entrelinhas" ${ }^{34}$, poderíamos dizer que o significado está “entre as isotopias do texto" ${ }^{35}$. E, indo um passo além, é possível dizer que o significado está no "oriente do texto”, e que ele "nasce" sob os olhos do leitor. Esse é o significado que o tradutor tem que traduzir, um significado que não está ligado a palavras representativas especiais no texto, como, por exemplo, é esclarecido por Gerzymisch:

Nós não podemos traduzir o "desespero" no [conto] Lenz de Georg Büchner (a menos que ele surja como uma expressão tangível), nós precisamos, para realizar a tradução, de uma manifestação do

\footnotetext{
32 HÖNIG, Hans. Die übersetzerrelevante Textanalyse. In: KöNIGS, Franck (ed.). Übersetzung und Fremdsprachenunterricht. München: Goethe-Institut, Ref. 42 - Arbeitsstelle für wissenschaftliche Didaktik. 1989.

${ }^{33}$ REIß, Katharina; VERMEER, Hans. Grundlegung einer Translationstheorie. Tübingen: Niemeyer, 1984.

34 SCHLEIERMACHER, Friedrich. Hermeneutik und Kritik. Mit einem Anhang sprachphilosophischer Texte Schleiermachers. Suhrkamp: Frankfurt, 1977, p. 315.

${ }^{35}$ STEFANINK; BĂLĂCESCU, op. cit., August/2017.

${ }^{36}$ RICCEUR, op. cit., 1975. p. 156.
} 
desespero como uma expressão concreta, que possamos transportar [de uma língua à outra]. É apenas essa expressão que podemos 'trans'-portar. ${ }^{37}$

A fim de compreender este significado, que está entre as isotopias do texto, temos que interpretar as unidades que são suscetíveis de carregar significado.

E é disto que trata a hermenêutica tradutória.

Vejamos agora como a necessidade pela Hermenêutica da Tradução desenvolveu-se ao longo da história.

\section{Hermenêtica: ciência ou arte?}

A hermenêutica pode ser definida como a ciência ou a arte da interpretação. A Hermenêutica da Tradução está intimamente ligada à hermenêutica filosófica, na medida em que a tradução pode ser vista como uma atualização da hermenêutica e vice-versa. A tradução realizada por Schleiermacher das obras de Platão serviu como base para sua hermenêutica filosófica. O problema fundamental tanto na hermenêutica filosófica quanto na Hermenêutica da Tradução é a legitimação em relação aos critérios "objetivos", tais como aplicam-se às ciências naturais. Assim, a história da hermenêutica pode ser entendida como uma luta para ser reconhecida como uma ciência ou como a rejeição desses esforços e a busca por sua identificação como uma arte. Mas essa definição não é nada simples. Até mesmo Heidegger ${ }^{38}$ sinalizou que a hermenêutica é "rätselhaft" [enigmática], e alguns hermeneutas nunca deixaram claro sua posição, na maior parte das vezes tendendo para o lado da categoria de arte no decorrer das suas pesquisas, como fez o emblemático representante da hermenêutica, Friedrich Schleiermacher, que passou a dar cada vez mais importância à "adivinhação mística" à medida que se aproximava do fim da vida.

\subsection{De grupos isolados de regras para a interpretação de áreas específicas para a universalização metodológica}

O status de ciência está relacionado ao desenvolvimento de uma metodologia que possa ser aplicada de modo universal. O primeiro a lutar por tal universalização foi Johann Conrad Dannhauer. Antes de Dannhauer, a interpretação de texto existia em íntima conexão à tradução de textos antigos do Latim e do Grego que alimentavam o pensamento medieval. Essas interpretações, porém, eram restritas a domínios específicos, tais como religião, filosofia, história, direito, medicina etc. A partir da observação da multiplicação dos escritos devido, por um lado, à invenção da imprensa e, por outro, à ideia renascentista de disseminação do conhecimento, que resultou em um envolvimento cada vez maior dos cientistas no processo de leitura, Dannauer vislumbrou a necessidade de um método universal para a interpretação de textos, desenvolvido por ele já em 1630 na obra - Idea boni interpretis et

\footnotetext{
${ }^{37}$ GERZYMISCH, Heidrun (ed.). Translation als Sinngebung. Münster: LitVerlag, 2013.

${ }^{38}$ HeIDEGGER, Martin. Unterwegs zur Sprache. Pfulligen: Neske, 1959, p. 98.
} 
malitiosi calumniatoris - onde ele introduziu o neologismo hermenêutica, possivelmente derivado do título da obra aristotélica Peri Hermeneias.

A iniciativa de Dannauer foi levada adiante no século XXVIII, quando a reflexão acerca da hermenêutica universal voltou-se para a discussão de minúcias tais como as origens da obscuridade em passagens complexas dos textos (Johann Martin Chladenius, 1710-1759) e também quando estendeu-se a ideia de hermenêutica universal para a semiótica geral (Georg Friedrich Meyer, 1718-1777), que considerava tudo que existia como um "sinal" apontando para algo escondido por trás de si mesmo, parte de um todo coerente desenhado por um Criador Divino.

No Século XIX, os estudos hermenêuticos foram dominados por um filósofo e teólogo geralmente considerado como o pai da hermenêutica moderna: Friedrich Schleiermacher. Na verdade, Schleiermacher "reinventou" a hermenêutica em seu caráter universal, aparentemente não tendo qualquer conhecimento acerca de seus predecessores nessa perspectiva, como podemos inferir pela carta enviada a seu amigo Ehrenfried von Willich, quando Schleiermacher começou a lecionar hermenêutica em 1805, na qual dizia não conseguir encontrar documentos voltados ao caráter universal da hermenêutica, salvo alguns conjuntos isolados de regras focalizando as diferentes áreas científicas ou religiosas.

Além de sua insistência no caráter universal da hermenêutica, o mérito de Schleiermacher foi o de estender o ato interpretativo para o todo do texto. Antes dele, a interpretação estava limitada às passagens obscuras de um texto. Após sua "hermenêutica dos equívocos", o texto como um todo torna-se passível de problemas de compreensão, e precisa ser interpretado, de forma que a interpretação equivocada de uma passagem obscura é preparada pela interpretação equivocada das passagens que a antecedem.

A hermenêutica filosófica de Schleiermacher nutriu-se de sua tradução de Platão e os problemas que daí surgiram, que o autor discutiu em sua correspondência com Schlegel, tentando apresentar "insights" teóricos a partir da prática tradutória, e deixando sua prática tradutória se beneficiar desses "insights". Assim, para o tradutor, o mérito de Schleiermacher foi transformar esse "insight" filosófico em algo relevante para a teoria tradutória. Isto é baseado no que Gadamer, citando Agostinho, chama de "mundo interno" [verbum interius], que é um significado que habita em nós e que "luta" para ser expressado. Este significado está sempre além das palavras com que tentamos expressá-lo. Como consequência, nenhuma possível expressão verbal deste significado pode ser compreendida como a representação última do mesmo. Há - como Heidegger postulará mais à frente - um Sinnüberschuss [excedente de significado] em todo texto. Esta é uma das diretrizes principais do pensamento hermenêutico.

Para o tradutor, isso significa que não existe algo como a tradução perfeita do texto fonte; existem apenas versões subjetivas provisórias correspondentes às representações mentais de significado na mente do tradutor em um determinado momento. Esta representação mental do significado é o verbum interius do tradutor, que se esforça para ser expresso nas palavras da língua alvo. Seguidores de Schleiermacher, como Wilhelm Dilthey (1833 - 1911), empenharam-se em superar esse aspecto subjetivo através do desenvolvimento de uma metodologia para a investigação do significado que, esperava-se, poderia garantir a objetividade nas ciências humanas, da mesma forma como o pensamento analítico o fez nas ciências naturais. 


\subsection{Questões contemporâneas no debate hermenêutico.}

Entretanto, Hans-Georg Gadamer $(1900$ - 2002) afastou completamente a ideia de uma tal metodologia. Para ele, o papel da hermenêutica não era de encontrar uma metodologia, mas de descobrir a verdade, seja através da linguagem ou através de obras de arte. O principal obstáculo para essa descoberta são nossos preconceitos. As filosofias racionalistas condenaram os preconceitos, concebendo-os como algo negativo. Para Gadamer, porém, os preconceitos fazem parte do processo de compreensão como algo inevitável que tem de ser integrado à abordagem teórica. Os preconceitos entravam nossa busca pela verdade quando são ignorados. Portanto, para Gadamer, o caminho para a verdade passa pelo diálogo, um dos fundamentos de sua hermenêutica. No diálogo com o outro, tornamo-nos conscientes de nossos próprios preconceitos e temos a possibilidade de reconsiderá-los e integrar a verdade do outro a nossa própria visão, em um processo que Gadamer chama de "fusão de horizontes". O que nos recorda as concepções de tradução de Berman ou Ricouer como um ato de "hospitalidade" à alteridade estrangeira. Para Gadamer, a compreensão é um progresso dinâmico e permanente que se dá em confronto dialético com o outro.

Para o tradutor, este "outro" é o texto. O tradutor precisa travar um diálogo com o texto. Gadamer retoma a metáfora do jogo de Wittgenstein e descreve o leitor como alguém que tem de entrar no jogo para entender o significado; ele precisa se envolver mais e mais no curso de sua leitura. Enquanto Schleiermacher dizia que "o significado está nas entrelinhas”, Gadamer diz que “o significado está por trás das palavras”. Para alcançá-lo, temos que desenvolver empatia (embora o próprio Gadamer nunca tenha usado este termo). O significado não é algo estático que possa ser apreendido através de mera análise intelectual.

Um exemplo dessa integração positiva do preconceito em uma construção positiva do significado durante o processo de tradução é apresentado por Stefanink e Bălăcescu ${ }^{39}$.

Todas estas ideias se tornaram valiosas para a tradução após a intervenção de Fritz Paepcke, cuja concepção de tradução - tomada de Gadamer - materializa-se em uma dinamização da terminologia dos estudos da tradução, quando fala, por exemplo, em Kommmunikationsgeschehen [o fato ou o processo da comunicação], Wahrheitsgeschehen [o fato ou o processo da verdade], etc., para chamar para o caráter dinâmico do significado. Paepcke apresenta termos como Leibhaftigkeit [corporalidade, fisicalidade sensível] do tradutor em sua compreensão, insistindo no envolvimento físico do tradutor com todos os seus sentidos, um aspecto que Douglas Robinson ${ }^{40}$ irá resumir no termo somática.

Com o trabalho de Paepcke, o tradutor, enquanto ser humano, foi colocado no centro das atenções, o que, no contexto do completo domínio do estruturalismo linguístico, representou uma pequena revolução dentro dos estudos da tradução. Requisitos fundamentais para a atividade do tradutor, como a "intuição" e a "criatividade", que haviam sido explicitamente banidos do pensamento teórico, já que "não se prestavam a uma abordagem

\footnotetext{
39 STEFANINK; BĂLĂCESCU, op. cit., 2015.

${ }^{40}$ RoBINSON, Douglas. The Translator's Turn. Baltimore/London: John Hopkins, 1991.
} 
sistemática" ${ }^{41}$, foram de súbito reincorporados a esse arcabouço como resultado da concepção de tradução de Paepcke. Mais do que isso, o status desses requisitos dentro de uma teoria da tradução tornou-se um marco para sua a avaliação de sua validade, qualidade e relevância para os profissionais da tradução ${ }^{42}$.

Entretanto, a impossibilidade de lidar com intuição e criatividade de um ponto de vista sistemático trouxe à tona preocupações com relação aos perigos da subjetividade na tradução e da consequente falta de cientificidade. Em vez de tentar negar a subjetividade do tradutor, a abordagem hermenêutica a integrou deliberadamente a seu pensamento teórico. No entanto, lidar com intuição e criatividade obrigou os hermeneutas a procurar novos critérios científicos para avaliação da qualidade na atividade tradutória.

Radegundis Stolze, discípulo de Paepcke na hermenêutica, recorreu à linguística como alternativa para emprestar um nível de estrutura fundamental às ideias disseminadas - por vezes não muito claramente formuladas ou mesmo contraditórias - que resultavam dos exemplos de tradução hermenêutica de Paepcke. Em seus vários livros sobre hermenêutica e tradução, ela destaca vários conceitos da hermenêutica filosófica (principalmente gadameriana) e explica sua relevância para o tradutor. Ela insiste no caráter holístico do processo de compreensão, em que o significado "überwältigt" [domina] o tradutor, levando-o a solucionar problemas de tradução em um impulso autopoiético e semiconsciente de formulação intuitiva na língua alvo. Essa concepção não a impediu de propor uma didática da tradução baseada em "campos de atenção" que guiariam o tradutor na execução de sua tarefa.

Entretando, lidar com a intuição e a criatividade, que é a questão central da hermenêutica tradutória, exige uma compreensão que vai além das fronteiras da linguística e adentra os novos campos da pesquisa cognitiva. Caso seja verdade que, de acordo com Heidegger, as "as palavras crescem para significados" [Den Bedeutungen wachsen Worte $z u$ ], a tradução hermenêutica está então condenada à criatividade. Se o significado está "entre as linhas", traduzir consiste em um processo de desverbalização, como proclamado pela teoria interpretativa defendida pela Escola de Paris, e em uma reformulação na língua alvo, que resulta em soluções mais ou menos criativas, na tentativa de "cristalizar" ${ }^{43}$ em novas palavras o significado que havia se desenvolvido entre as isotopias do texto fonte no processo de interpretação, como pode ser deduzido a partir das observações feitas sobre o processo tradutório com ajuda de uma metodologia empírica e centrada em corpus, oriunda da sociologia e introduzida na abordagem hermenêutica por Stefanink ${ }^{44}$ : a análise etnometodológica da conversação.

A introdução da subjetividade, da intuição e da criatividade como fundamentais para os estudos da hermenêuticos da tradução fez surgir a preocupação sobre o caráter científico da abordagem hermenêutica. Para "objetivistas" não-hermeneutas, a cientificidade estava ligada à rastreabilidade dos diferentes passos dados para alcançar um resultado. Segundo eles, esta rastreabilidade não está presente na abordagem hermenêutica ${ }^{45}$. Essa

\footnotetext{
${ }^{41}$ GerZymisch-Arbogast, Heidrun; MudersbaCH, Klaus. Methoden des wissenschaflichen Übersetzens. Tübingen: Francke, 1998, p. 16.

42 STEFANINK; BĂLĂCESCU, op. cit., 2015, p. 600.

${ }^{43}$ STEFANINK; BĂLĂCESCU, op. cit., August/2017.

44 STEFANINK, Bernd. L'ethnotraductologie au service d'un enseignement de la traduction centré sur l'apprenant. Le langage et l'homme, 4. 1995. pp. 265-293.

${ }^{45}$ GerZYMISCH, Heidrun (ed.). Translation als Sinngebung. Münster: LitVerlag, 2013. p. 73.
} 
posição, entretanto, ignora os esforços de pesquisa recentes na direção de uma Verwissenschaftlichung [cientificização] $^{46}$ da hermenêutica tradutória. Certamente, Popper $^{47}$ não limita o caráter científico de um método à previsibilidade dos resultados (o que negaria a cientificidade dos inventores); ao contrário, Popper afirma que o caráter científico da pesquisa é garantido por uma metodologia a posteriori, caso o inventor seja capaz de rastrear e explicar os diferentes passos que o levaram à tal invenção. Isto é o que as pesquisas recentes em Hermenêutica da Tradução têm buscado fazer ao recorrer não apenas à análise linguística, mas também aa pesquisas recentes na área dos estudos cognitivos.

A metodologia empregada por essa nova abordagem foi baseada no trabalho de pesquisadores americanos na área das ciências sociais na década de 1970, como descrito por Garfinkel ${ }^{48}$ : a análise etnometodológica de conversação, tal como é empregada na área da etnociência. Consiste do estudo das representações ingênuas que o usuário comum da língua exprime por trás das palavras que ele ou ela emprega, especialmente em conversas sobre elementos da vida cotidiana que despertam sua imaginação, como, por exemplo "as mulheres e homens de branco", que se tornou um campo de investigação para a etnomedicina. Stefanink ${ }^{49}$ introduziu esta metodologia nos estudos da tradução sob o título de ethnotraductologie [etnotradutologia], em língua francesa. Ela consiste na "negociação" de uma tradução por dois ou mais tradutores, com o objetivo de alcançar uma versão comum na língua alvo com que ambos concordem. Esta metodologia oferece não apenas a possibilidade de se estudar o processo tradutório, mas também expõe as representações ingênuas que os tradutores envolvidos têm sobre o processo tradutório, a língua e a relação entre cultura e língua, etc.

Além disso, essa abordagem é muito eficiente de um ponto de vista didático. Depois de transcrever seus diálogos, os participantes os analisam com a ajuda de seus instrutores, situação na qual eles são confrontados com suas ideias ingênuas acerca do processo de tradução, da linguagem, da relação entre cultura e linguagem, etc. Tal conscientização é muito eficiente e convincente, conforme demonstrado em Balacescu/Stefanink ${ }^{50}$, onde foi demonstrado, a um grupo de tradutores do francês para o córsico que se recusou a acatar qualquer abordagem teórica, que na base da resolução de seus problemas tradutórios havia alguns elementos teóricos, dispersos, desconexos e aleatórios, mas responsáveis por suas tomadas de decisão.

Esses novos elementos na teoria da tradução exigem novos critérios para a avaliação de qualidade. Enquanto abordagens analíticas podem apoiar-se em etapas (aparentemente) racionais e lógicas que levam a uma (ilusória) "objetividade", a abordagem hermenêutica apoia-se no que podemos chamar (no contexto dos estudos filosóficossociais de Jurgem Habermas) konsensuelle Wahrheit [verdade consensual]. Para o tradutor, isso significa que ele tem

\footnotetext{
${ }^{46}$ CERCEL, Larisa. Übersetzungshermeneutik. Historische und systematische Grundlegung. Saint-Ingbert: Röhrig, 2013, p. 122149.

47 POPPER, Karl R. Logik der Forschung. Wien: Springer, 1966, p. 7-8.

${ }^{48}$ GARFINKEL, Harold. Studies in Ethnomethodology. Cambridge: Blackwell, 1984.

49 STEFANINK, op. cit, 1995.

50 BĂLĂCESCU, Ioana; STEFANINK, Bernd. Une approche théorique pour la traduction. In: THIERS, Ghjacumu (ed.). Baratti. Commentaires et réflexions sur la traduction de la poésie. Albiana - Bu - Ccu - Iitm.S. 2003. pp. 24-77.
} 
que alcançar uma "intersubjektive Nachvollziehbarkeit" [plausibilidade/rastreabilidade inter-subjetiva] ${ }^{51}$; tem que convencer aos "especialistas" 52 , seus colegas tradutores da mesma área, da validade da sua tradução, especialmente nos casos em que soluções criativas se fizeram necessárias.

\section{Exemplo de resolução hermenêutica criativa de um problema tradutório com base na pesquisa cognitiva}

Um grupo de estudantes alemães deviam traduzir um texto do alemão para o inglês, em um contexto de descrição dos problemas dos jovens casais com filhos em que ambos os pais trabalham.

They had to juggle two careers and a potty-chair.

Os estudantes traduziram potty-chair como

1. Windelwecheln (trocar fraldas): duas carreiras e trocar fraldas

2. Kind (filhos): duas carreiras e filhos

O que aconteceu? No contexto de educação infantil das nações de língua inglesa, a palavra potty-chair remete a um elemento muito comum, que é lexicalizado em idiomatismos como potty-chair training. De acordo com as cenas $e$ quadros semânticos de Charles Fillmore ${ }^{53}$, o quadro linguístico potty-chair desencadeia na mente do tradutor a "cena" manuseio de excrementos. Eleonor Rosch ${ }^{54}$ nos informa que, em cada categoria, você tem um elemento que lhe é prototípico; a teoria do alinhamento entre figura e base de outro cognitivista, Ronald Langacker ${ }^{55}$, propõe que o relacionamento entre esse elemento prototípico, que o autor denomina figura, e o conhecimento prévio, que ele designa por base, pode mudar e é diferente de uma cultura para outra. Na Inglaterra, o elemento prototípico emblemático nessa cena é o troninho, na Alemanha é a troca de fraldas. De acordo com o cognitivista Roger Schank $^{56}$, ambos fazem parte do que ele chama de PMOs (Pacotes de Memória Organizacional). A memória do tradutor bi-cultural havia registrado a cena do manuseio de excrementos, que contêm tanto os elementos de troninho e troca de fraldas. O tradutor, sabendo das diferenças entre essas expressões no caráter prototípico da cultura inglesa

\footnotetext{
51 STEFAninK, Bernd. 'Esprit de finesse' und 'esprit de géométrie': Das Verhältnis von 'Intuition' und 'übersetzerrelevanter Textanalyse' beim Übersetzen. In: KELLER, Rudi. Linguistik und Literaturübersetzen. 1997.

52 RISKU, Hanna. Translatorische Kompetenz. Kognitive Grundlagen des Übersetzens als Expertentätigkeit. Tübingen: Stauffenburg, 1998.

${ }^{53}$ FILLMORE, op. cit., 1976.

${ }^{54}$ RosCh, Eleanor. Cognitive Psychology. Cognitive Psychology, 4, 1973. pp. 328-350.

${ }^{55}$ LANGACKER, Ronald W. Foundations of Cognitive Grammar. Stanford: Stanford University Press, 1987.

${ }^{56}$ SCHANK, Roger, C. Dynamic Memory. A Theory of Reminding and Learning in Computers and People, London/New York: Cambridge University Press, 1982.
} 
quando comparado à cultura alemã, realiza a substituição que se faz necessária para manter o "Wirkungsgleichheit" [efeito de equivalência] ${ }^{57}$, na cultura alvo.

A tradução por Kind estabelece a equivalência em um nível superior. De fato, a palavra Kind pode ser vista como um atalho para o cenário Kindererziehung [educação infantil]. A cadeira com penico é um dos elementos desse cenário de Kindererziehung, por isso parece plausível, de acordo com a teoria dos Pacotes de Organização Temática [POT] de Roger Schank, segundo a qual o tradutor associa esse elemento da cena ao cenário de Kindererziehung, que inclui esse elemento cênico da cadeira com penico, que pertence ao cenário do gerenciamento de excrementos. A teoria da organização da memória também teria possibilitado a tradução como Fläschchen geben [alimentação com mamadeira], porque esse é outro elemento do cenário da educação infantil. No esquema a seguir, as reticências indicam cenas alternativas pertencentes ao cenário da educação infantil. ${ }^{58}$

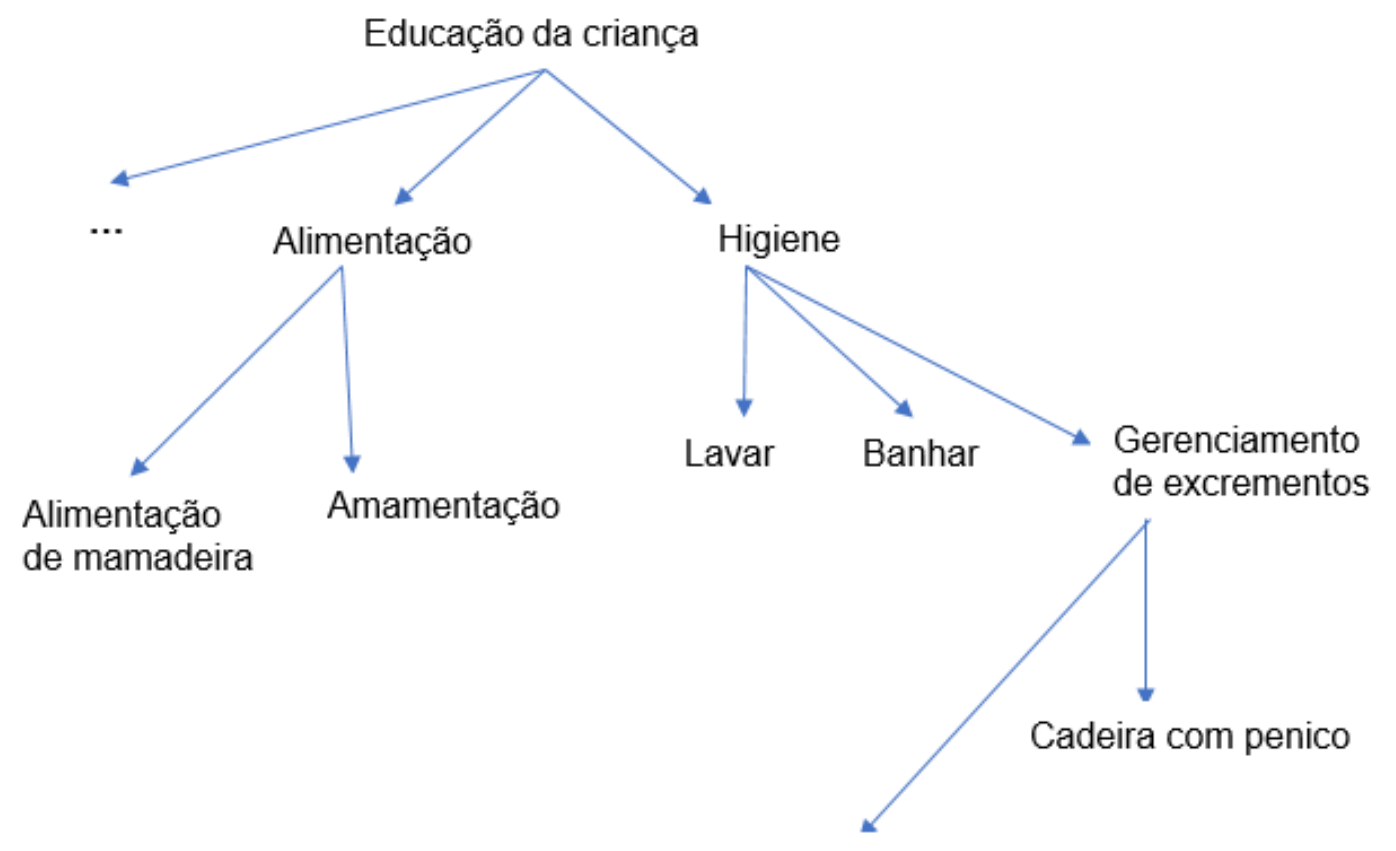

Trocar a fralda

Como pode ser observado, as relações entre as diferentes cenas são de natureza associativa e, como Fillmore ${ }^{59}$ explana: "cenas e quadros são mutuamente recuperáveis, o que significa que uma cena pode ativar seu quadro associado e um quadro pode ativar sua cena associada". Devemos nos lembrar também que o conceito de "cena" de Fillmore, assim como o de um quadro linguístico, é bastante amplo semanticamente, oferecendo ao tradutor um vasto potencial de encadeamentos neurais associativos como uma forma de explicar suas soluções para problemas criativos:

\footnotetext{
${ }^{57}$ REIß, Katharina; VERMEER, Hans. Grundlegung einer Translationstheorie. Tübingen: Niemeyer, 1984.

${ }^{58}$ NOTA DA TRADUTORA: O mais usual em português brasileiro padrão é "alimentação com/por mamadeira".

${ }^{59}$ FILLMORE, op. cit., 1976, p. 64.
} 
Eu quero dizer que as pessoas, quando estão aprendendo uma língua, associam determinadas cenas a determinados quadros linguísticos. Eu quero usar a palavra cena - uma palavra com a qual não fico totalmente satisfeito - no sentido mais geral possível, para incluir não apenas cenas visuais, mas tipos familiares de interações interpessoais, cenários padrão, estruturas familiares e institucionais, experiências enativas, imagens corporais; e, em geral, todo e qualquer tipo de segmento coerente, grande ou pequeno, de crenças, ações, experiências ou imaginários humanos. Eu pretendo usar a palavra quadro para referir-me a qualquer sistema de escolhas linguísticas (os casos mais fáceis sendo as sequências de palavras, mas incluindo também a seleção de regras ou categorias gramaticais) que pode ser associado a instâncias prototípicas de cenas. [...] Eu gostaria de dizer que as cenas e os quadros, nas mentes das pessoas que aprenderam as associações entre estes, ativam um ao outro; e que, além disso, os quadros são associados a outros quadros devido ao seu material linguístico em comum e que as cenas são associadas umas com outras cenas devido à uniformidade ou similaridade das entidades ou relações ou substâncias presentes nestas ou em seus contextos de ocorrência. ${ }^{60}$

Todas estas explicações oferecidas pela ciência cognitiva legitimam a criatividade que auxilia o tradutor hermeneuta a superar as barreiras culturais. A hermenêutica afirma: você deve sentir o texto com todos os seus sentidos, deve deixar-se ser dominado pelo significado que você sente, e então você deve fazer com que este significado seja compreendido pelos outros, e para tal você necessita do suporte da análise linguística e da ciência cognitiva. A análise linguística permite que você perceba o que desencadeou sua solução criativa a partir dos elementos "bottom up" do texto, a ciência cognitiva o ajuda a compreender e fazer que os outros compreendam quais os processos de encadeamento associativos induziram tal solução.

\subsection{Perspectivas Euturas}

Perspectivas para o futuro: uma melhor cooperação entre filósofos e tradutores pode beneficiar ambas as disciplinas. Schleiermacher estabeleceu a hermenêutica filosófica a partir de sua discussão com Schlegel sobre a tradução de Platão. Teóricos da tradução contemporâneos - como, por exemplo, Paepcke - têm se alimentado do trabalho de filósofos como Gadamer, embora o interesse dos filósofos hermeneutas pela tradução seja muito limitado (como percebemos no último simpósio de filósofos em Florianópolis, Hermeneia, 2015). Esqueceram que as ideias de Schleiermacher sobre a hermenêutica vieram de sua tradução de Platão e suas discussões com Schlegel sobre tal tradução? Apenas Paul Ricoeur tem clamado por uma aplicação da hermenêutica filosófica em diferentes campos científicos, o que não tem acontecido até agora, porém.

Ao final de sua summa, Cercel $^{61}$ lamenta sobre a presente falta de reconhecimento pela qual a Hermenêutica da Tradução tem passado, e nos convida a envidar esforços para que ela seja mais aceita. Concordamos completamente

\footnotetext{
${ }^{60}$ FILLMORE, op.cit., 1976, pp. 63.

${ }^{61}$ CERCEL, Larisa. Übersetzungshermeneutik. Historische und systematische Grundlegung. Saint-Ingbert: Röhrig, 2013 , p. 364.
} 
com sua crítica quando ela afirma, no entanto, que "Dazu gehört mehr als plakative Aussagen” [Isso requer mais do que afirmações abstratas]; compreendemos essa asserção como um convite para a realização de mais pesquisas empíricas como, por exemplo, Stefanink e Bălăcescu ${ }^{62}$.

Acreditamos que o desafio de tornar a Hermenêutica da Tradução mais convincente pode ser vencido, por um lado, em um nível empírico, através da multiplicação de estudos individuais que tratem do processo tradutório (especialmente da solução criativa de problemas) com a ajuda da análise conversacional etnometodológica, que ofereceria uma base sólida para discussões sobre o extensivamente discutido processo de compreensão - actio vs. passio $^{63}$, o papel da intuição, etc. - e daria mais estofo a formulações fundamentais como a de Heidegger, que afirma que "Den Bedeutungen wachsen Worte zu” [As palavras florescem dentro de seus significados]. Foi o que tentamos ilustrar, por exemplo, em Stefanink and Bălăcescu ${ }^{64}$.

Por outro lado, o contato interdisciplinar com as ciências cognitivas também seria benéfico, já que estas últimas confirmam a função heurística da hermenêutica. O que de fato é o processo cognitivo "de baixo pra cima/de cima pra baixo" se não a Horizontverschmelzung [fusão de horizontes] gadameriana? E o que é o roteiro cognitivista de Schank ${ }^{65}$ se não a pré-compreensão hermenêutica, o Vorverständnis [pré-conceito] de Heidegger? Além disso, a defesa de Gadamer de um uso positivo deste Voruteil [pré-juízo] no processo de compreensão pode ser também encontrado nas ideias de Lakoff ${ }^{66}$ sobre categorização. Quanto à "subjetividade" de que se acusa a abordagem hermenêutica, que está ligada ao círculo hermenêutico, sua inevitabilidade é provada de maneira convincente pela pesquisa neurofilosófica de Hans Lenk ${ }^{67}$ em Schemainterpretationismus [Interpretacionismo do esquema].

A criação recente de um centro de pesquisas em "Hermenêutica e criatividade" na universidade de Saarbrücken há três anos, bem como a criação recente do centro de pesquisa TRACO (Tradução e Cognição) na Universidade Johannes Gutenberg em Mainz/Germersheim (2016) podem ser consideradas materializações institucionais desta tendência interdisciplinar e são a confirmação da validade de nossa pesquisa neste campo.

\section{Referências}

AitCHISON, Jean: Words in the Mind. An Introduction to the Mental Lexicon. Oxford: Blackwell, 2003.

${ }^{62}$ STEFANINK; BĂLĂCESCU, op. cit., 2015.

STEFANINK; BĂLĂCESCU, op. cit., August/2017.

${ }^{63}$ CERCEL, Larisa. Übersetzungshermeneutik. Historische und systematische Grundlegung. Saint-Ingbert: Röhrig, 2013 , p. 153.

${ }^{64}$ STEFANINK; BĂLĂCESCU, op. cit, 2015.

STEFANINK; BĂLĂCESCU, op. cit, August/2017.

${ }^{65}$ SCHANK, Roger, C. Dynamic Memory. A Theory of Reminding and Learning in Computers and People, London/New York: Cambridge University Press, 1982.

${ }^{66}$ LAKoff, George; Johnson, Mark. Women, Fire and Dangerous Things. What Categories Reveal about The Mind. Chicago: University of Chicago Press, 1987, p. 5.

67 LENK, Hans. Methodologischer chemainterpretationismus: Erkenntnistheoretisches zur Einführung. In: PAUL, Gregor. Transkulturelle Logik. Universalität in der Vielfalt. Bochum Freiburg: Projektverlag, 2014, p 78. 
BĂLĂCESCU, Ioana; STEFANINK, Bernd. Une approche théorique pour la traduction. In: THIERS, Ghjacumu (ed.). Baratti. Commentaires et réflexions sur la traduction de la poésie. Albiana - Bu - Ccu - Iitm.S. 2003. pp. 24-77.

(2012): De la valeur heuristique du terme dans l'approche herméneutique. In: CERCEL, Larisa; STANLEY, John. Unterwegs zu einer hermeneutischen Übersetzungswissenschaft. Radegundis Stolze zu ihrem 60. Geburtstag. Tübingen: Narr., 2012.

(2006): Kognitivismus und übersetzerische Kreativität. In: Lebende Sprachen n.2. 2006. pp. 50-60.

Rev. of Heidrun Gerzymisch: Translation als Sinngebung (Münster: LitVerlag, 2013). In: Lebende Sprachen 59.1, 2014. pp. 188-207

BourdieU, Pierre. Le Sens pratique. Paris: Les Éditions de Minuit, 1980.

BÜHLER, Hildegund (éd.). Translators and their Position in Society: Proceedings of the Xth World Congress of FIT. Wien: Wilhelm Braumüller, 1985.

CATFORD, J. C. A Linguistic Theory of Translation. An Essay in Applied Linguistics. London, 1965.

CERCEL, Larisa. Übersetzungshermeneutik. Historische und systematische Grundlegung. Saint-Ingbert: Röhrig, 2013.

COSERIU, Eugenio. Einführung in die Textlinguistik. (org. and ed. V. J.

Albrecht). Tübingen: Narr., 1980.

DE BONO, E. Lateral Thinking. A Textbook of Creativity. London: Ward Lock Educational, 1970.

DURIEUX, Christine. Vers un théorie décisionnelle de la traduction. Revue LISA, vol.III, n.3, 2009.

FILlmoRe, Charles. Scenes-and-Frames Semantics. In: ZAMPOldI, Antonio (dir.) Linguistic Structures Processing, Amsterdam: N. Holland, 1976. pp. 55-88.

GADAMER, Hans-Georg. Wahrheit und Methode. Grundzüge einer philosophischen Hermeneutik. Tübingen: J.C.B. Mohr, 1960.

GARFINKEL, Harold. Studies in Ethnomethodology. Cambridge: Blackwell, 1984.

GERZYMISCH-ARBOGAST, Heidrun (1994): Übersetzungswissenschaftliches Propädeutikum. Tübingen: Francke (UTB 1782)

GERZYMisCH-ARBOGAST, Heidrun; MudersBACH, Klaus. Methoden des wissenschaflichen Übersetzens. Tübingen: Francke, 1998.

GERZYMISCH, Heidrun (ed.). Translation als Sinngebung. Münster: LitVerlag, 2013.

GRONDIN, Jean. Einführung in die Hermeneutik. Darmstadt: Wissenschaftliche Buchgesellschaft, 2001/2012.

Grondin, Jean. Paul Ricœur. [Que sais-je ?] Paris: PUF, 2013.

GuILFORD, Joy Peter. Creativity: A Quarter Century of Progress. In: TAYLOR, Irving A.; GeTZELs, Jacob W. (eds). Perspectives in Creativity. Chicago: Aldine, 1975. pp. 37-59.

HABERMAS, Jürgen. Moralbewußtsein und kommunikatives Handeln. Frankfurt am Main: Suhrkamp, 1983.

HeIDEGGER, Martin (2008): Being and Time (transl. John MacQuarrie and Edward Robinson). New York and London: Harper and Row, 2008.

Sein und Zeit. Tübingen: Niemeyer, 1927/1967.

Unterwegs zur Sprache. Pfulligen: Neske, 1959. 
HöNIG, Hans. Die übersetzerrelevante Textanalyse. In: KÖNIGS, Franck (ed.). Übersetzung und Fremdsprachenunterricht. München: Goethe-Institut, Ref. 42 - Arbeitsstelle für wissenschaftliche Didaktik. 1989. IONESCU, Tudor. Le traducteur herméneute. In: IONESCU, Marina Mureşanu. Actes. Journées de la francophonie. IVème édition, Iaşi: Editura universității “Alexandru Ioan Cuza”, 1998. pp. 111-114. . Tudor. Ştiința sau/arta traducerii [La science ou/et l'art de la traduction]. Cluj-Napoca: Editura Limes, 2003.

KADE, Otto. Zufall und Gesetzmäßigkeit in der Übersetzung, Leipzig: VEB Verlag Enzyklopädie, 1968.

KANT, Immanuel. Kritik der reinen Vernunft, Werke in zwölf Bänden, Band 3, Frankfurt am Main: Suhrkamp, 1977 (or. publ. 1787).

Kohlmayer, Rainer. Die Stimme im Text als tertium comparationis beim Literaturübersetzen. In: STOLZE, Radegundis; STANLEY, John; CERCEL, Larisa (eds). Translational Hermeneutics. The First Symposium. Bucureşti: Zeta Books, 2015. pp. 235-255.

KRINGS, Hans Peter. Was in den Köpfen von Übersetzern vorgeht. Eine empirischeUntersuchung zur Struktur des Übersetzungsprozesses an fortgeschrittenen Französischlernern. Tübingen: Narr, 1986.

KußMAUL, Paul. Kreatives Übersetzen. Tübingen: Stauffenburg, 2000.

LADMIRAL, Jean-René. La philosophie et la traduction. In: BATCHELOR, Kathryn; GILONNE, Yves (eds). Translating Thought/Traduire la pensée. Nottingham: University of Nottingham, 2010. pp. 6-16.

LAKOFF, George; Johnson, Mark. Metaphors We Live By. Chicago: University of Chicago Press, 1980.

Women, Fire and Dangerous Things. What Categories Reveal about The Mind. Chicago: University of Chicago Press, 1987.

LANGACKER, Ronald W. Foundations of Cognitive Grammar. Stanford: Stanford University Press, 1987.

LENK, Hans. Methodologischer chemainterpretationismus: Erkenntnistheoretisches zur Einführung. In: PAUL, Gregor. Transkulturelle Logik. Universalität in der Vielfalt. Bochum Freiburg: Projektverlag, 2014. pp. 71-98.

Mounin, Georges. Les problèmes théoriques de la traduction. Paris: Gallimard, 1963.

NIDA, Eugene A. Translating Means Translating Meaning - A Sociosemiotic Approach to Translating. In: BÜHLER, Hildegund (éd.). Translators and their Position in Society: Proceedings of the Xth World Congress of FIT. Wien: Wilhelm Braumüller, 1985.

Semantic Structure and Translating. In: WILSS, W.; THOME, G. Aspekte der theoretischen sprachbezogenen und angewandten Uebersetzungswissenschaft II, Heidelberg: Groos, 1974. p. 50.

O’KeEfFe, Brian. Prologue to a Hermeneutic Approach to Translation. In: STOlZE, Radegundis; STANLEY, John; CerCEL, Larisa (eds). Translational Hermeneutics. The First Symposium. București: Zeta Books. 2015. pp. 145-177.

PAEPCKE, Fritz. Übersetzen als hermeneutischer Entwurf. In: Im Übersetzen leben. Übersetzen und Textvergleich: Tübingen: Narr, 1986. pp. 86-101.

POPPER, Karl R. Logik der Forschung. Wien: Springer, 1966.

REIß, Katharina; VERMEER, Hans. Grundlegung einer Translationstheorie. Tübingen: Niemeyer, 1984.

RICEUn, Paul. Du texte à l'action. Paris: Seuil, 1986.

Ecrits et Conférences. II. Herméneutique. Paris: Seuil. 2010. 
La Métaphore vive. Paris: Seuil, 1975.

RISKU, Hanna. Translatorische Kompetenz. Kognitive Grundlagen des Übersetzens als Expertentätigkeit. Tübingen: Stauffenburg, 1998.

RoBInson, Douglas. The Translator's Turn. Baltimore/London: John Hopkins, 1991.

RosCH, Eleanor. Cognitive Psychology. Cognitive Psychology, 4, 1973. pp. 328-350.

SCHADE, Ulrich. Konnektionismus: Zur Modellierung der Sprachproduktion. Opladen: Westdeutscher Verlag, 1992.

SchAnk, Roger, C. Dynamic Memory. A Theory of Reminding and Learning in Computers and People, London/New York: Cambridge University Press, 1982.

SCHLEIERMACHER, Friedrich. Hermeneutik und Kritik. Mit einem Anhang sprachphilosophischer Texte Schleiermachers. Suhrkamp: Frankfurt, 1977.

STEFANINK, Bernd; BĂLĂCESCU, Ioana. Le verbum interius du traducteur et la cristallisation du sens. META 62. 2. August/2017, 290-314.

Les cheminements de la créativité en traduction. META 60.3. 2015. pp. 599-620.

STEFANINK, Bernd. 'Esprit de finesse' und 'esprit de géométrie': Das Verhältnis von 'Intuition' und 'übersetzerrelevanter Textanalyse' beim Übersetzen. In: KELLER, Rudi. Linguistik und Literaturübersetzen. 1997. pp. 161-183.

L'ethnotraductologie au service d'un enseignement de la traduction centré sur l'apprenant. Le langage et l'homme, 4. 1995. pp. 265-293.

Stolze, Radegundis; Stanley, John; CerCel, Larisa (eds). Translational Hermeneutics. The First Symposium. Bucureşti: Zeta Books, 2015.

STOLZE, Radegundis. Hermeneutik und Translation. Tübingen: Narr, 2003.

The Translator's Approach - Introduction to Translational Hermeneutics. Berlin: Frank \& Timme, 2011.

Recebido em: 05 de abril de 2021.

Aceito em: 05 de maio de 2021. 